\title{
Sonic Anemometer Comparison and Measurements in the Atmospheric Surface Layer
}

\author{
By J.A. Businger and M. Miyake* \\ University of Washington, Seattle, Washington \\ E. Inoue \\ National Institute of Agricultural Sciences, Tokyo \\ Y. Mitsuta and T. Hanafusa \\ Kyoto University, Kyoto \\ (Manuscript received 10 July 1967, in revised form 1 November 1968)
}

\begin{abstract}
Results of comparison measurements of a sonic anemometer developed at Kyoto University and one developed at the University of Washington are presented. Good agreement between the instruments has been obtained.

Several techniques of data reduction have been applied. Comparison between the digital and analogue techniques gave consistent results.

Besides comparison measurements, general observations of atmospheric turbulence are presented including variance spectra of the vertical wind component $w$ and temperature $T$. for various . stabilities, and cospectra as well as coherence between $w$ and $T$.
\end{abstract}

\section{Introduction}

In the past 20 years several techniques to measure turbulent fluctuations and turbulent fluxes directly in the atmospheric boundary layer have been developed. These measurements are difficult to, make accurately mainly because no calibration technique is available in the atmosphere. To gain confidence in the various methods, it is necessary to carry out comparison tests between instruments that measure the same turbulent quantity independently.

With this objective in mind, a comparison experiment was organized under the auspices of the U.S.-Japan cooperative program which is jointly supported by NSF and JSPS. The instruments used for this comparison were a continuous wave sonic anemometer developed at the University of Washington which has been described by Kaimal and Businger (1963), and a pulse type sonic anemometer developed at Kyoto University which has been described by Mitsuta (1966).

Two experiments were carried out in the summer of 1965. One near Hanford, Washington, where the supporting data of mean profiles were

\footnotetext{
* Present affiliation: University of British Columbia
}

provided by the Atmospheric Sciences Section of Battelle-Northwest, and one near Liberal, Kansas, where the Air Force Cambridge Research Laboratories have based a site for micrometeorological studies.

\section{Field experiments}

The Hanford experiment. The observations were carried out during 1 and 2 July 1965 at the Hanford micrometeorological site. The site is characterized by rolling plains sparsely covered with sage brush and grass. It has been described in detail by Barad et. al. (1962). The site is not as horizontally homogeneous as some experimental sites in Australia and Kansas, but its location is close to Seattle, Washington, and the available facilities made it rather convenient to use for the experiment.

The sonic anemometers were mounted on a 32 $m$ mast which was equipped with instrumentation to measure the wind and temperature profiles. See Figs. 1 and 2. Both instruments had an array of $50 \mathrm{~cm}$ over which the vertical wind and temperature was measured. The horizontal separation between the instruments was about $25 \mathrm{~cm}$. The analog signals from the instruments were recorded on magnetic tape and monitored on a 


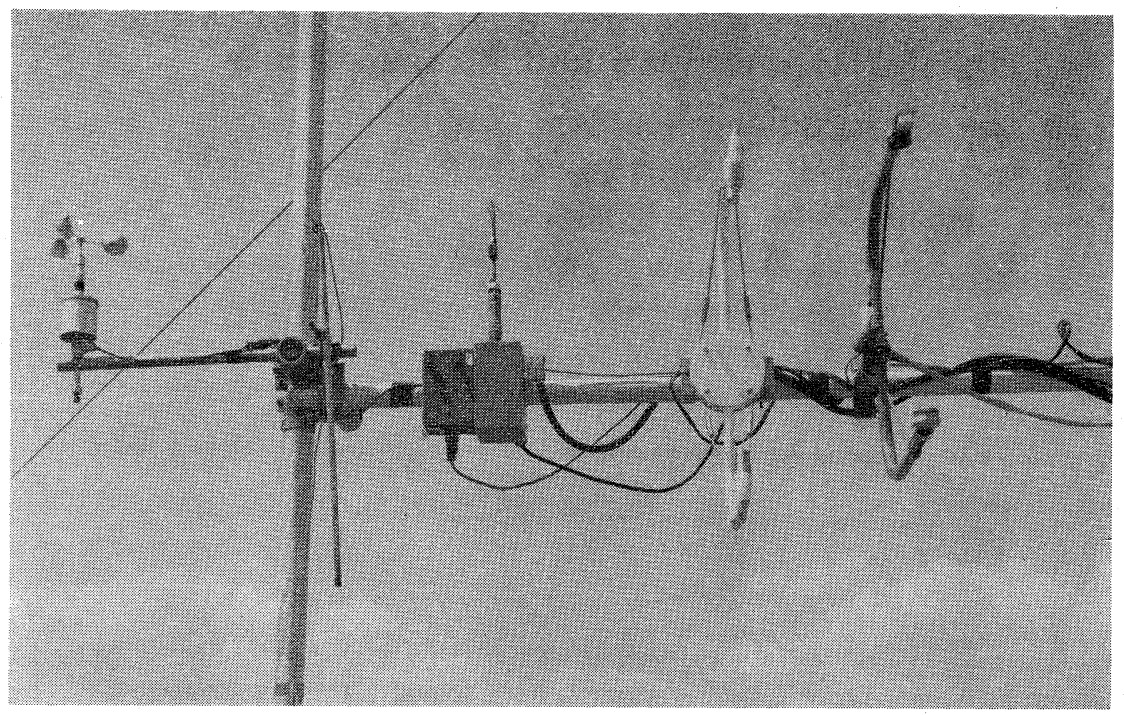

Fig. 1. Mounting of the two sonic arrays for the comparison run. The array on the far right is the University of Washington instrument. Next to it is the Kyoto University array. The instrument in the middle is the so-called component meter, which is a hot wire anemometer that measures the three wind components and automatically orients itself into the mean wind. Observations taken with this instrument are not included in this paper.

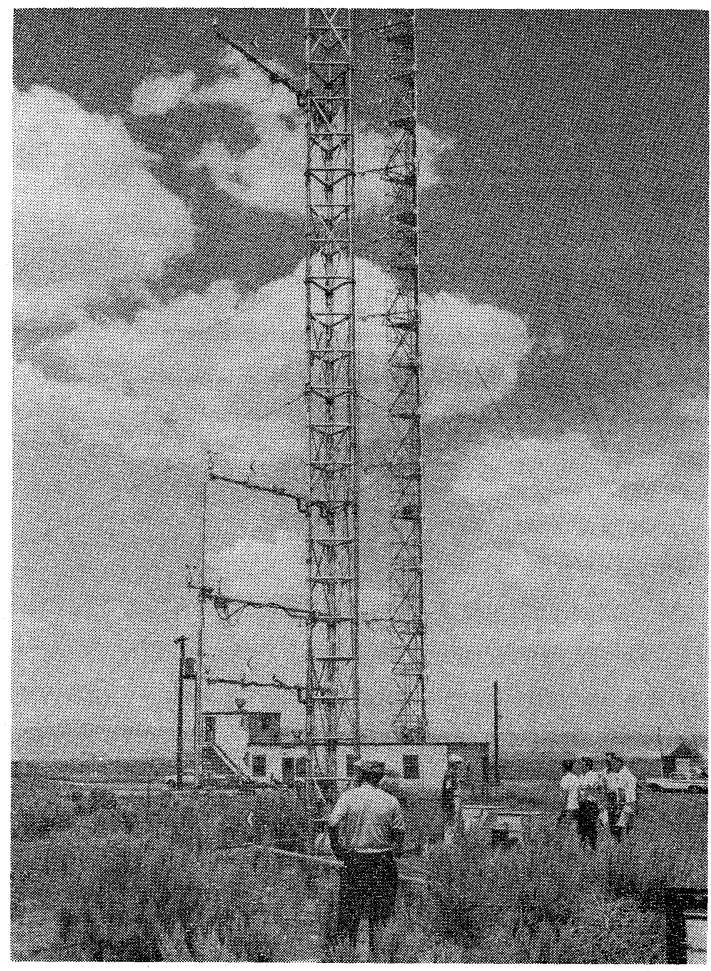

Fig. 2. Micrometeorological towers at the Hanford site. The University of Washington sonic array is mounted in this picture at about 1.5 $\mathrm{m}$, whereas the Kyoto University array is at about $11 \mathrm{~m}$.

strip chart recorder. A sample of the vertical wind recording for both instruments is given in Fig. 3. Four signals from both sonic anemometers representing vertical wind and temperature were multiplexed with an I.R.I.G. system, and

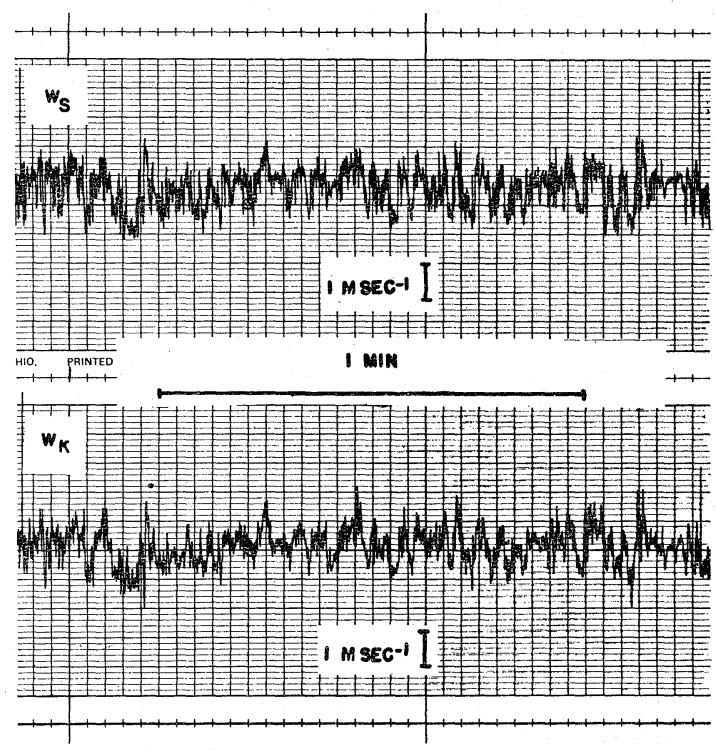

Fig. 3. Simultaneous output of $w$ from both sonic anemometer shows good agreement of the signals. The traces are part of $\mathrm{K}-1$.

recorded on one channel of $1 / 4^{\prime \prime}$ high fidelity tape recorder. Another channel of this tape recorder was used for voice information about the experiment.

The Kansas experiment. The period of observation was 21-24 August 1965. The site is one of the flattest areas in the U.S. One square mile of flat land has been leased by the A.F.C.R.L. The surface is either stubble or fallow, but very uniform. During our experiment the southern half of the area was stubble and the northern half was fallow. The wind is predominantly 
from the south, therefore the fetch to the instruments was over stubble. In the center of this area called "Windy Acres," a 32m tower which was equipped to measure the wind and temperature profiles has been erected. A detailed description of the site and the micrometeorological facility has been given by the Boundary Layer Branch of A.F.C.R.L. (1967).

The purpose of this experiment was mainly to obtain some representative fluctuating data from which the statistics of turbulence could be determined.

The data were recorded in a similar way as during the Hanford experiment.

\section{Data reduction techniques}

Description. Three methods of data reduction have been applied to the observations.

1. Analog values from the strip chart were manually digitised on punch cards. Computation of mean values, variances, covariances and spectra were carried out by digital computer (IBM 7094). The mathematical scheme used in the spectrum computations is that of Tukey, see Blackman and Tukey (1958).

2. Analog values from magnetic tape were fed into an A-D converter (Beckman 210 at the U.S. Army Electronics Command at Fort Huachuca, Arizona). The automatically digitised data were handled by digital computer in the same way as under 1 .

3. The analog tapes were processed with an analog computer. To do this, the tapes were repeatedly rerecorded compressing the data in time up to 1024 times. A complete run of 30 to 40 minutes of observation time was compressed this way into a single loop of 6 to 8 feet which allowed for fast and continuous reproduction of the run as needed for the analog computations. Before entering the Systron-Donner S/D 80 anlaog computer, the data were passed through KrohnHite variable band pass filters. The output of the analog computer then consisted of variances and covariances determined over various spectral intervals and from this the spectral and cospectral estimates were determined.

Comparison analog-digital methods. In order to satisfy ourselves and the reader that the analog and digital methods yield consistent results, a few runs have been analysed by both methods. The runs selected were Kansas 4 and 7. The spectra of the vertical velocity component $w$ and of tem- perature $T$, for both these runs are plotted in Figs. 4 and 5. The digital analysis was carried out in two parts for run 4 and in three parts for
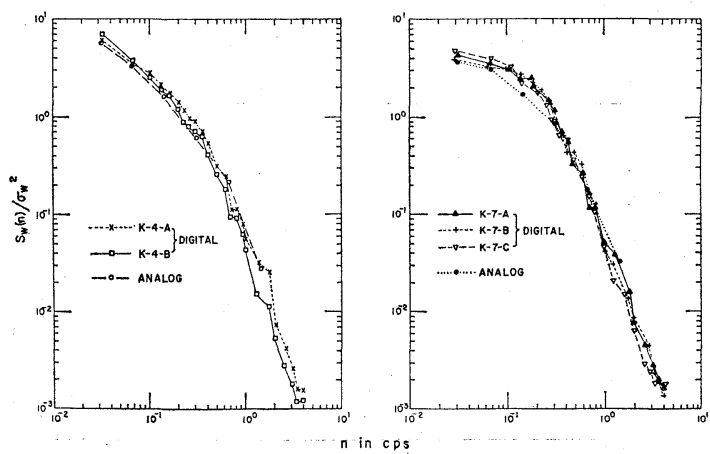

Fig. 4. Normalized variance spectra of the vertical wind component for $\mathrm{K}-4$ and K-7 obtained with both digital and analog methods.
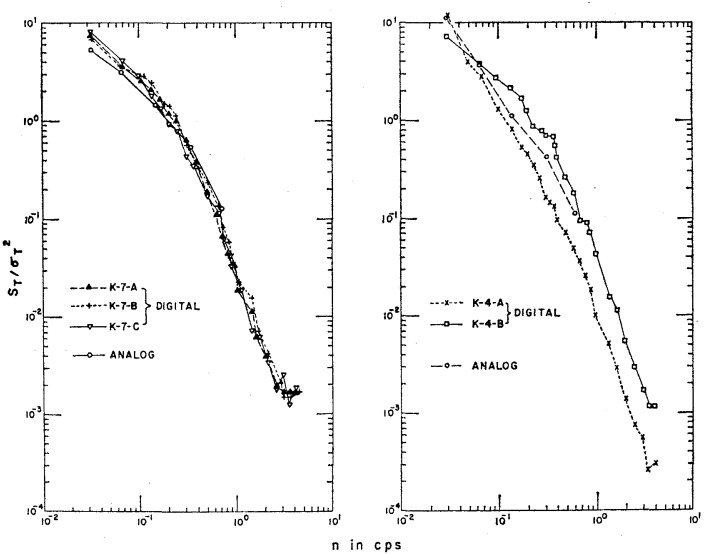

Fig. 5. Normalized variance spectra of temperature for K-4 and K-7 obtained with both digital and analog methods.

run 7. The agreement between the two methods is very satisfactory. The filter band used in the analog method is considerably wider than the mathematical filter used in the digital method. As a consequence, the curvatures of the analogspectra are less sharp than those of the digitalspectra. The digital temperature spectra of run 4 show a systematical difference indicating that the variance over the second half of the total period is larger than over the first half. The analog spectrum estimates over the full period fall in between the two digital values as expected.

\section{Comparison of sonic anemometers}

The first objective of the experiment was to 
compare the performance of the two sonic anemometers. Several comparison runs were made both at Hanford and in Kansas. When both instruments were operating satisfactorily the agreement was good. Figures 6 and 7 show the coherence

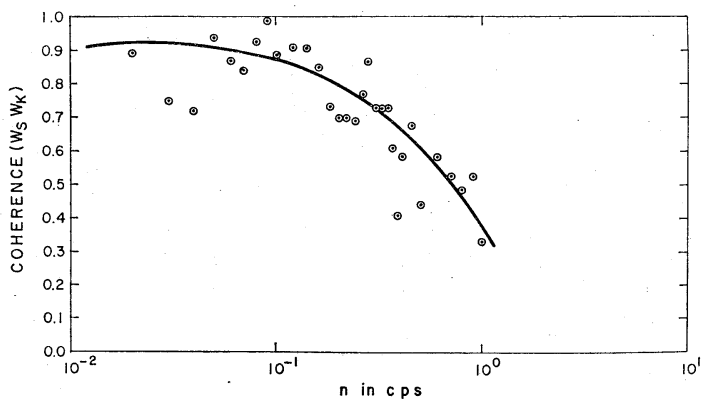

Fig. 6. Coherence between $w_{S}$ and $w_{K}$ for part of $\mathrm{H}-1$ which showed good agreement.

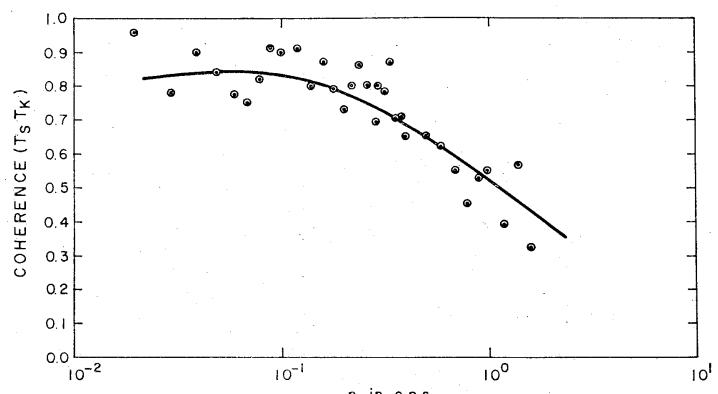

Fig. 7. Coherence between $T_{S}$ and $T_{K}$ for part of $\mathrm{H}-1$ which showed good agreement.

for $w_{s}$ and $w_{k}$, and $T_{s}$ and $T_{k}$, respectively. The indices $S$ and $K$ refer to Seattle and Kyoto, respectively, indicating the origin of the sonic anemometer. Although the distance between the arrays was quite small (about $25 \mathrm{~cm}$, see Fig. 1), the coherence decreases markedly from $0.1 \mathrm{cps}$ to 1 cps. Apparently a horizontal displacement of $25 \mathrm{~cm}$ in the lateral or cross wind direction is already felt at relatively low frequencies. The wind was rather light during this run, $1.8 \mathrm{~m} \mathrm{sec}^{-1}$ at $4 \mathrm{~m}$ height; consequently, the entire spectra were at relatively low frequencies. Unfortunately, more extensive comparison was not possible because during the following comparison runs the U.W. sonic anemometer did not function properly. This was detected afterwards because we were not able to monitor all the channels simultaneously. But because the preliminary monitored charts indicated good agreement, the experiment was continued with the two sonic anemometers at different heights.

Further comparison information was obtained at the Kansas site. During the first two runs of this experiment, the two sonic anemometers were put side by side in a similar way as was done at Hanford (see Fig. 1). These runs were of good quality and excellent agreement between $w_{\mathrm{S}}$ and $w_{K}$ was obtained.

However, the heat flux was so small that the noise level of the system was of the same magnitude as the signal. The results of these two runs are summarized in Table 1 . It is clear

Table. 1. Comparison of the two sonic anemometers

\begin{tabular}{|c|c|c|c|}
\hline & & Run K-1 & Run K-2 \\
\hline$\overline{w^{\prime} s^{2}}$ & $(\mathrm{~cm} / \mathrm{sec})^{2}$ & $2.84 \times 10^{3}$ & $2.29 \times 10^{3}$ \\
\hline$\overline{w_{K}^{\prime}{ }^{2}}$ & $(\mathrm{~cm} / \mathrm{sec})^{2}$ & $2.47 \times 10^{3}$ & $1.88 \times 10^{3}$ \\
\hline$\overline{T^{\prime} S^{2}}$ & $\left({ }^{\circ} \mathrm{C}\right)^{2}$ & $8.52 \times 10^{-2}$ & $2.52 \times 10^{-2}$ \\
\hline$\overline{T_{K}^{\prime}{ }^{2}}$ & $\left({ }^{\circ} \mathrm{C}\right)^{2}$ & $2.22 \times 10^{-1}$ & $8.90 \times 10^{-2}$ \\
\hline$\overline{T^{\prime} h^{2}}$ & $\left({ }^{\circ} \mathrm{C}\right)^{2}$ & $1.17 \times 10^{-1}$ & $2.44 \times 10^{-2}$ \\
\hline$\rho c p \overline{w_{S}{ }^{\prime} T_{S}}{ }^{\prime}$ & $\left(\mathrm{mWcm}^{-2}\right)$ & $6.90 \times 10^{0}$ & $2.24 \times 10^{0}$ \\
\hline$\rho c p{\overline{w_{K}} T_{K}}^{\prime}$ & $\left(\mathrm{mWcm}^{-2}\right)$ & $4.25 \times 10^{-2}$ & $-4.12 \times 10^{0}$ \\
\hline$\rho c p \overline{w_{S}{ }^{\prime} T_{h}}{ }^{\prime}$ & $\left(\mathrm{mWcm}^{-2}\right)$ & $8.06 \times 10^{0}$ & $5.31 \times 10^{-1}$ \\
\hline$\rho c p \bar{w}_{K}^{\prime} T_{h}^{\prime}$ & $\left(\mathrm{mWcm}^{-2}\right)$ & $3.91 \times 10^{0}$ & $3.26 \times 10^{-1}$ \\
\hline$\frac{\overline{w_{K}^{\prime} w_{S}^{\prime}}}{\sqrt{W_{K}^{2 \prime}} \sqrt{w_{S}}}$ & & 0.86 & 0.86 \\
\hline$\frac{-\overline{T_{K} T_{S}^{\prime}}}{\sqrt{T_{K}{ }^{2 \prime}} \sqrt{T_{S}}}$ & & 0.57 & -0.03 \\
\hline
\end{tabular}

from both the correlations and the magnitudes of $w_{S}$ and $w_{K}$ that agreement is satisfactory. The coherence of $w_{S}$ and $w_{K}$ are given in Fig. 8. The fact that the variances of $w_{S}$ and $w_{K}$ differ by about $15 \%$ is somewhat more than desirable, but the cospectra are in excellent agreement. This indicates that there may be a systematic

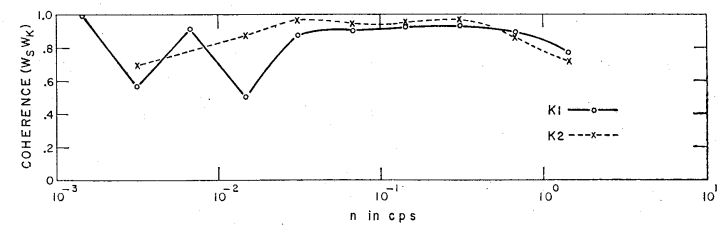

Fig. 8. Coherence between $w_{\mathrm{S}}$ and $w_{K}$ for K-1 : and $\mathrm{K}-2$.

difference in the calibrations. To investigate this aspect more closely, the variance spectra of $w_{S}$ and $w_{K}$ are plotted in Fig. 9. The $w_{S}$ spectra 
Table 2. Hanford obsevations 1965

\begin{tabular}{|c|c|c|c|c|c|c|c|c|c|c|c|c|c|c|c|}
\hline Run & Date & Time & $\begin{array}{c}\text { Mean } \\
\text { profile } \\
\text { of }\end{array}$ & 0.8 & 1.5 & $\begin{array}{c}\text { Height } \\
3.0\end{array}$ & $\begin{array}{l}\text { in } \mathrm{m} \\
6.1\end{array}$ & 12.2 & 24.4 & $\begin{array}{r}z_{0} \\
\mathrm{~cm}\end{array}$ & $\begin{array}{l}\mathrm{Ri} \text { at } \\
400 \mathrm{~cm}\end{array}$ & $\mathrm{~cm}_{/ \sec ^{-1}} \mathrm{~m}$ & $\begin{array}{c}F_{h} \\
\mathrm{nW} / \mathrm{cm}^{-2}\end{array}$ & $\begin{array}{c}\sigma_{w} \\
\mathrm{~cm} \\
/ \mathrm{sec}^{-1}\end{array}$ & $\begin{array}{l}\sigma_{T} \\
{ }^{\circ} \mathrm{C} \\
\end{array}$ \\
\hline \multirow[t]{2}{*}{$\mathrm{H}-1 \mathrm{~A}$} & 1 June & 10.43 & $\mathrm{u} \mathrm{m} / \mathrm{sec}$ & 1.4 & 1.6 & 1.9 & 2.1 & 2.2 & 2.3 & 4.7 & -1.04 & 23.6 & 30.8 & 34 & 0.5 \\
\hline & to & o 10.52 & $\mathrm{~T}$ in ${ }^{\circ} \mathrm{C}$ & 30.0 & 29.5 & 28.8 & 28.0 & 28.0 & 27.8 & & & & & & \\
\hline \multirow[t]{2}{*}{$\mathrm{H}-1 \mathrm{~B}$} & & 10.56 & $\mathrm{u}$ & 1.3 & 1.5 & 1.7 & 1.9 & 1.9 & 2.0 & 3.1 & -1.56 & 19.8 & 31.9 & 35 & \\
\hline & & o 11.06 & $\mathrm{~T}$ & 29.9 & 28.9 & 28.3 & 28.3 & 28.2 & 28.0 & & & & & & \\
\hline \multirow[t]{2}{*}{$\mathrm{H}-4 \mathrm{~A}$} & & 19.02 & $\mathrm{u}$ & 3.6 & 4.7 & 5.4 & 6.3 & 7.1 & 8.4 & & 0.006 & 648.0 & -1.8 & 46 & \\
\hline & & o 19.15 & $\mathrm{~T}$ & 29.7 & 29.8 & 29.8 & 29.9 & 29.8 & 29.9 & & & & & & \\
\hline \multirow[t]{2}{*}{$\mathrm{H}-4 \mathrm{~B}$} & & 19.16 & $\mathrm{u}$ & 3.4 & 4.4 & 5.1 & 5.9 & 6.6 & 7.7 & & 0.014 & 441.4 & -2.4 & 38 & \\
\hline & & o 19.29 & $\mathrm{~T}$ & 28.9 & 29.2 & 29.2 & 29.3 & 29.2 & 29.3 & & & & & & \\
\hline \multirow[t]{2}{*}{$\mathrm{H}-5$} & & 20.12 & $\mathrm{u}$ & 3.7 & 4.8 & 5.5 & 6.3 & 7.0 & 8.3 & & 0.017 & 741.6 & -3.2 & 64 & \\
\hline & & 21.20 & $\mathrm{~T}$ & 27.8 & 28.1 & 28.2 & 28.3 & 28.2 & 28.3 & & & & & & \\
\hline \multirow[t]{2}{*}{ H-9 } & 2 June & 10.48 & $\mathrm{u}$ & 2.1 & 2.3 & 3.0 & 3.3 & 3.5 & 3.7 & 6.0 & -0.41 & 34.9 & 31.9 & 23 & \\
\hline & & 10.53 & $\mathrm{~T}$ & 31.6 & 30.4 & 29.5 & 29.7 & 29.2 & 28.7 & & & & & & \\
\hline \multirow[t]{2}{*}{$\mathrm{H}-10 \mathrm{~A}$} & & 12.03 & $\mathrm{u}$ & 1.7 & 1.9 & 2.1 & 2.3 & 2.4 & 2.5 & 1.8 & -1.21 & 20.8 & 23.6 & 50 & \\
\hline & & to 12.16 & $\mathrm{~T}$ & 32.9 & 32.4 & 31.6 & 31.5 & 31.1 & 30.9 & & & & & & \\
\hline \multirow[t]{2}{*}{$\mathrm{H}-10 \mathrm{~B}$} & & 12.23 & $\mathrm{u}$ & 1.6 & 1.9 & 2.2 & 2.3 & 2.3 & 2.3 & 1.9 & -1.05 & 20.6 & 19.2 & 71 & \\
\hline & & to 12.36 & $\mathrm{~T}$ & 33.5 & 32.8 & 32.0 & 32.2 & 31.9 & 31.5 & & & & & & \\
\hline \multirow[t]{2}{*}{$\mathrm{H}-11$} & . & 13.40 & $\mathrm{u}$ & 1.6 & 2.4 & 2.7 & 3.0 & 3.1 & 3.4 & 6.8 & -0.32 & 31.9 & 25.1 & 54 & \\
\hline & & o 14.04 & $\mathrm{~T}$ & 35.4 & 34.2 & 34.0 & 33.3 & 33.2 & 32.8 & & & & & & \\
\hline \multirow[t]{2}{*}{$\mathrm{H}-13 \mathrm{~A}$} & & 15.52 & $\mathrm{u}$ & 2.1 & 2.5 & 2.9 & 3.3 & 3.4 & 3.7 & 3.7 & 0.295 & 29.6 & 17.4 & 53 & \\
\hline & & 016.02 & $\mathrm{~T}$ & 34.9 & 34.8 & 34.3 & 33.7 & 33.3 & 33.1 & & & & & & \\
\hline \multirow[t]{2}{*}{ H-13B } & & 16.05 & $\mathrm{u}$ & 2.7 & 3.3 & 3.9 & 4.6 & 5.0 & 5.5 & 6.8 & -0.154 & 45.8 & 33.3 & 45 & \\
\hline & & to 16.18 & $\mathrm{~T}$ & 35.6 & 34.7 & 34.3 & 33.6 & 33.0 & 32.7 & & & & & & \\
\hline
\end{tabular}

Table 3. Kansas observations 23 Aug. 1965

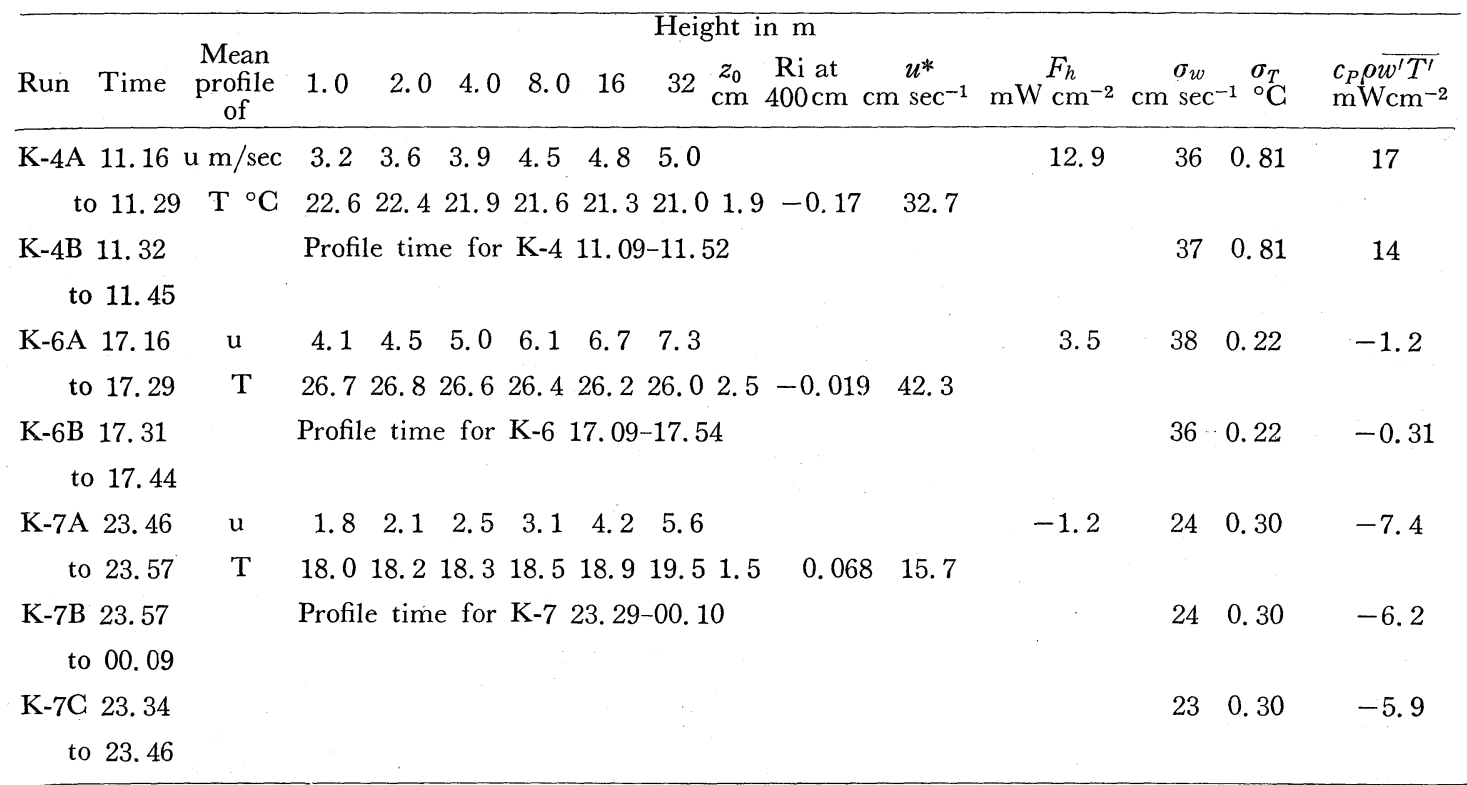




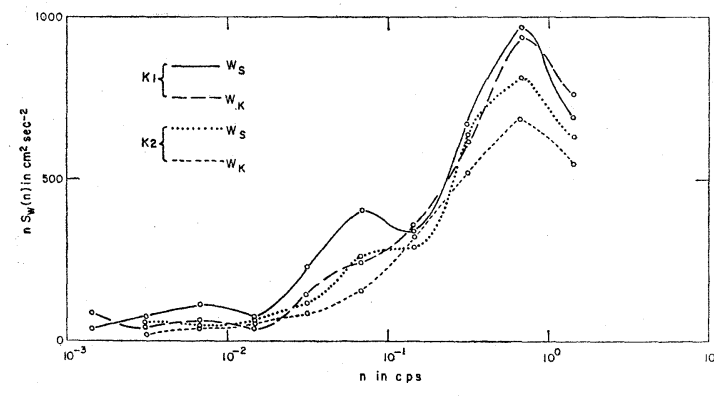

Fig. 9. Absolute variance spectra of $w$ for $\mathrm{K}-1 \mathrm{~K}-2$.

show a secondary maximum of $0.07 \mathrm{cps}$ which is absent in the $w_{K}$ spectra. This is probably caused by the mixture of the second harmonics of both acoustic channels $(7.5 \mathrm{kc}$ and $5 \mathrm{kc})$ of the Washington sonic anemometer interfering with the $5 \mathrm{kc}$ signal, because $15 \mathrm{kc}-10 \mathrm{kc}=5 \mathrm{kc}$. Besides this secondary maximum, the $w_{S}$ spectra are systematically higher by a small amount which is probably within the range of errors of the data reduction procedure. It is of interest to note that the maxima of the spectra are of the relatively high frequencies of $0.6 \mathrm{cps}$.

In order to get some insight in the behavior of the temperature observations, the output of a the thermocouple which was mounted in between the sonic array was analysed. The variance of temperature during run 2 was negligible and consequently the resulting heat fluxes are not

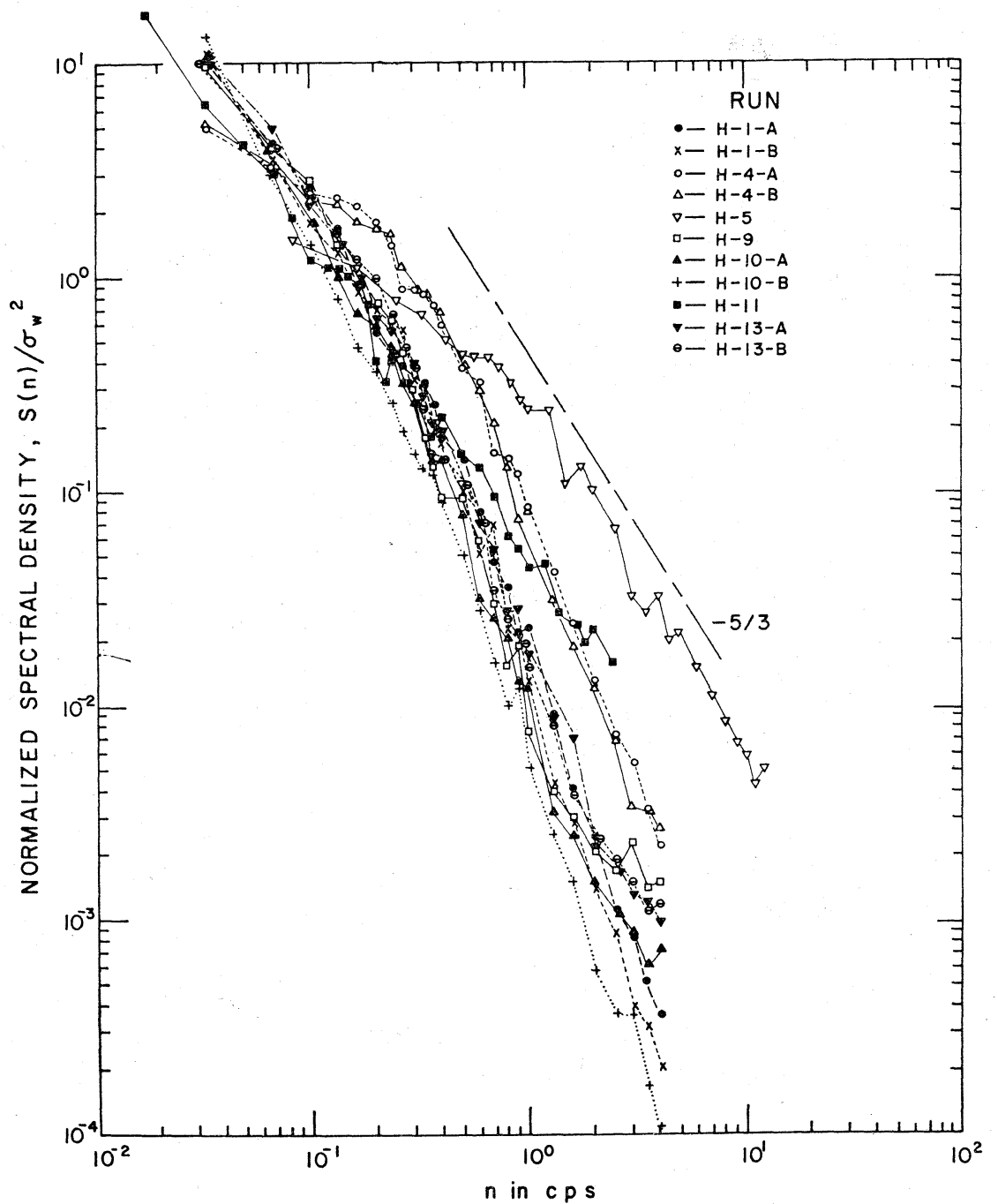

Fig. 10. Normalized $w$ spectra for a selected number of Hanford runs. $\mathrm{H}-5$ and $\mathrm{H}-11$ were digitised by hand. 


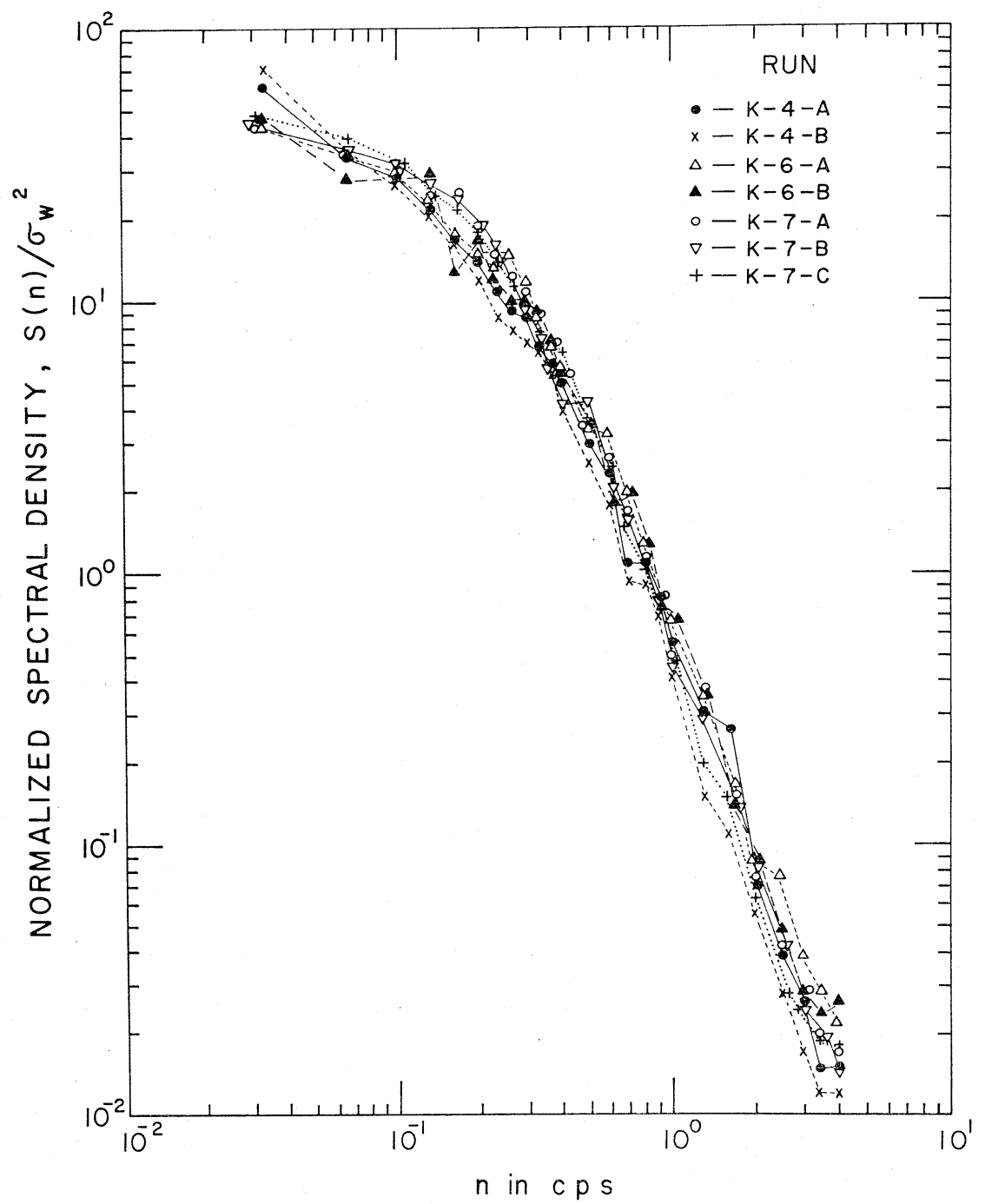

Fig. 11. $w$ spectra for a selected number of Kansas runs.

significant for this run. However, the variances and heat fluxes for run 1 were significant, although not large. The heat flux obtained with $w_{S}{ }^{\prime} T_{S}{ }^{\prime}$ and $w_{S}{ }^{\prime} T_{h}{ }^{\prime}$, where $T_{h^{\prime}}$ is the thermocouple temperature, agree within $15 \%$ which suggests that these values approximate the true values. The agreement between $w_{K}^{\prime} T_{K}^{\prime}$ and $w_{K}^{\prime} T_{h}^{\prime}$ is poor. It seems that $w_{K}^{\prime} T_{K}^{\prime}$ is systematically low.

\section{General results}

Vertical wind component. Most of the runs were digitised after the Kansas experiment. The duration of sampling for computing the spectra in digital form, as a rule, 800 sec., and the sampling time $0.1 \mathrm{sec}$. Two of the Hanford runs
( $\mathrm{H}-5$ and $\mathrm{H}-11$ ) were digitised from the strip chart recording of the Kyoto sonic anemometer. For run $\mathrm{H}-5$, the sampling duration was $200 \mathrm{sec}$ and the sampling time $0.04 \mathrm{sec}$; for run $\mathrm{H}-11$, the sampling duration was $600 \mathrm{sec}$. and sampling time $0.2 \mathrm{sec}$. The total duration of the runs was usually about 40 minutes, so several sampling periods could be taken from each run. A selection was made of those periods that appeared most stationary in time.

The profile data that correspond to the selected runs have been summarized in Tables 2 and 3 for Hanford and Kansas, respctively. The profiles were analysed using the Businger-Dyer representation for the unstable cases and the log-linear 


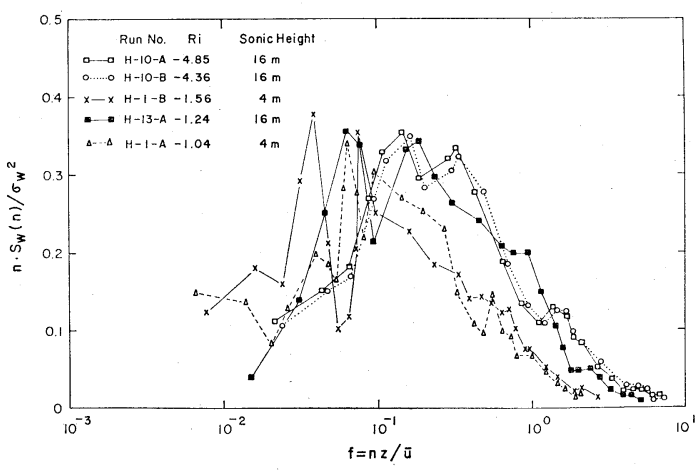

Fig. 12. Normalized $w$ spectra for very unstable cases.

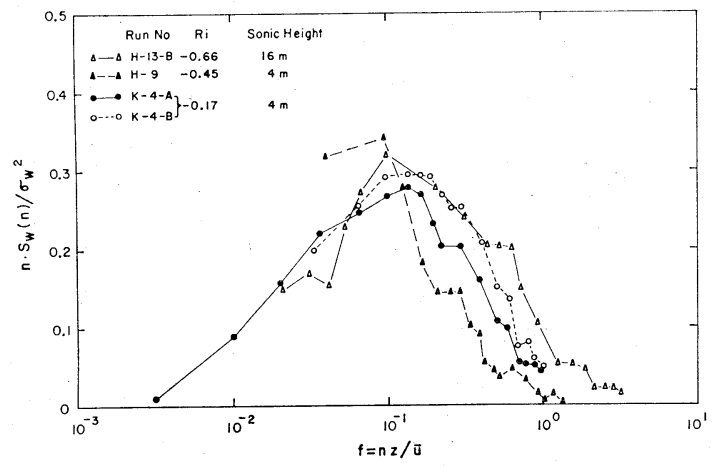

Fig. 13. Normalized $w$ spectra for moderately unstable cases.

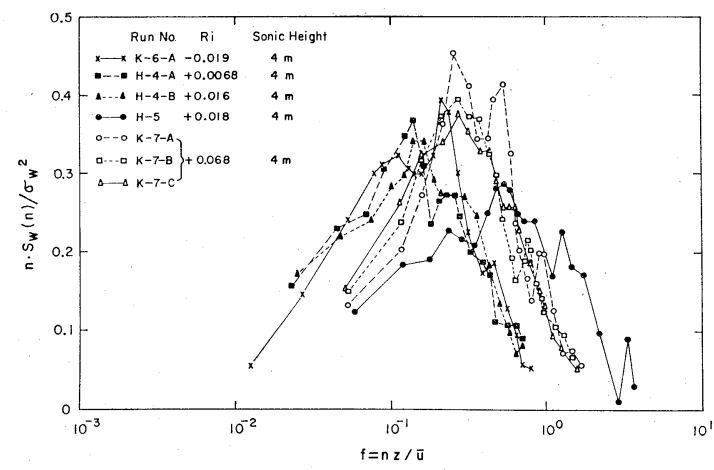

Fig. 14. Normalized $w$ spectra for neutral and slightly stable cases.

representation for the stable cases. The procedure for the analysis has been described by Paulson (1967). The profile information of wind and temperature is analysed simultaneously and the roughness $z_{0}$, the friction velocity $u_{*}$, and the heat flux $F_{h}$ are solved by curve fitting of the assumed profile shapes. For the Kansas runs in Table 3. comparison between $F_{h}$ as determined from proflle and as determined by Kyoto sonic

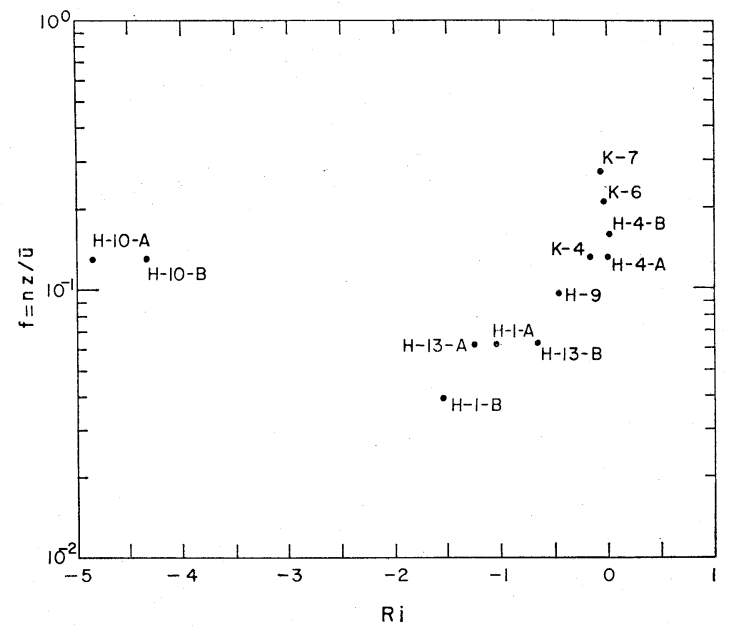

Fig. 15. A plot of the normalized frequency of the spectral maxima taken from Figures 12-14 versus the $\mathrm{Ri}$-number.

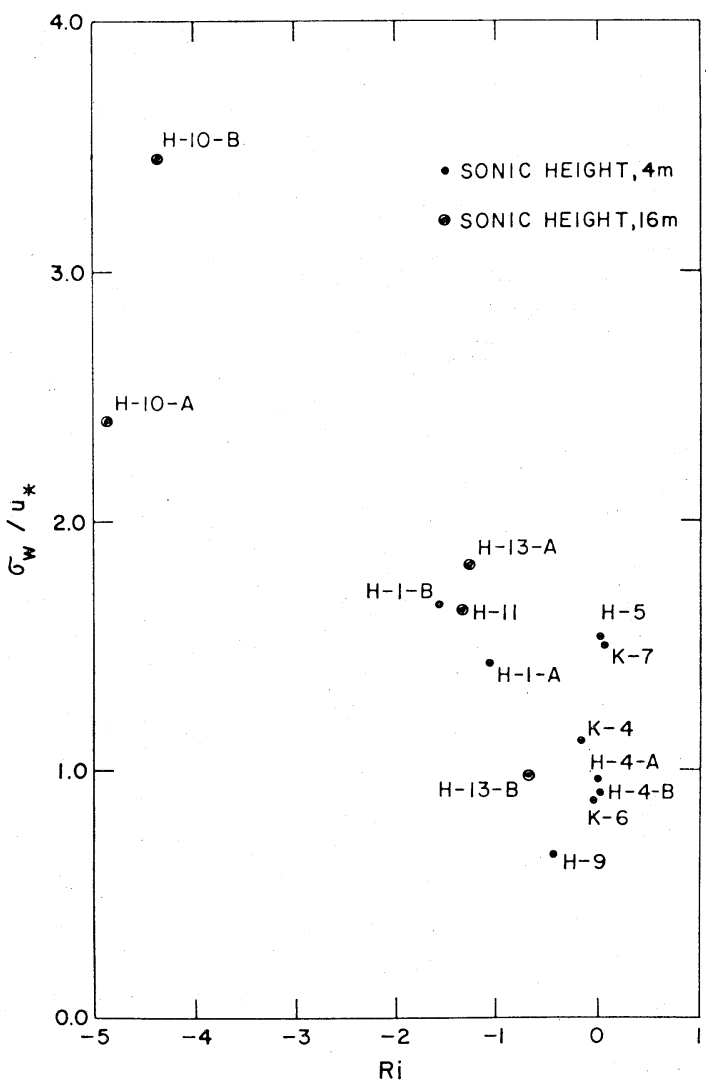

Fig. 16. $\sigma_{w} / u_{*}$ as a function of $\mathrm{Ri}$.

anemometer can be made. The unstable run $\mathrm{K}-4$ is in fair agreement. Run $\mathrm{K}-6$ indicates a small upward flux according to the profiles and a small downward flux according to the sonic 


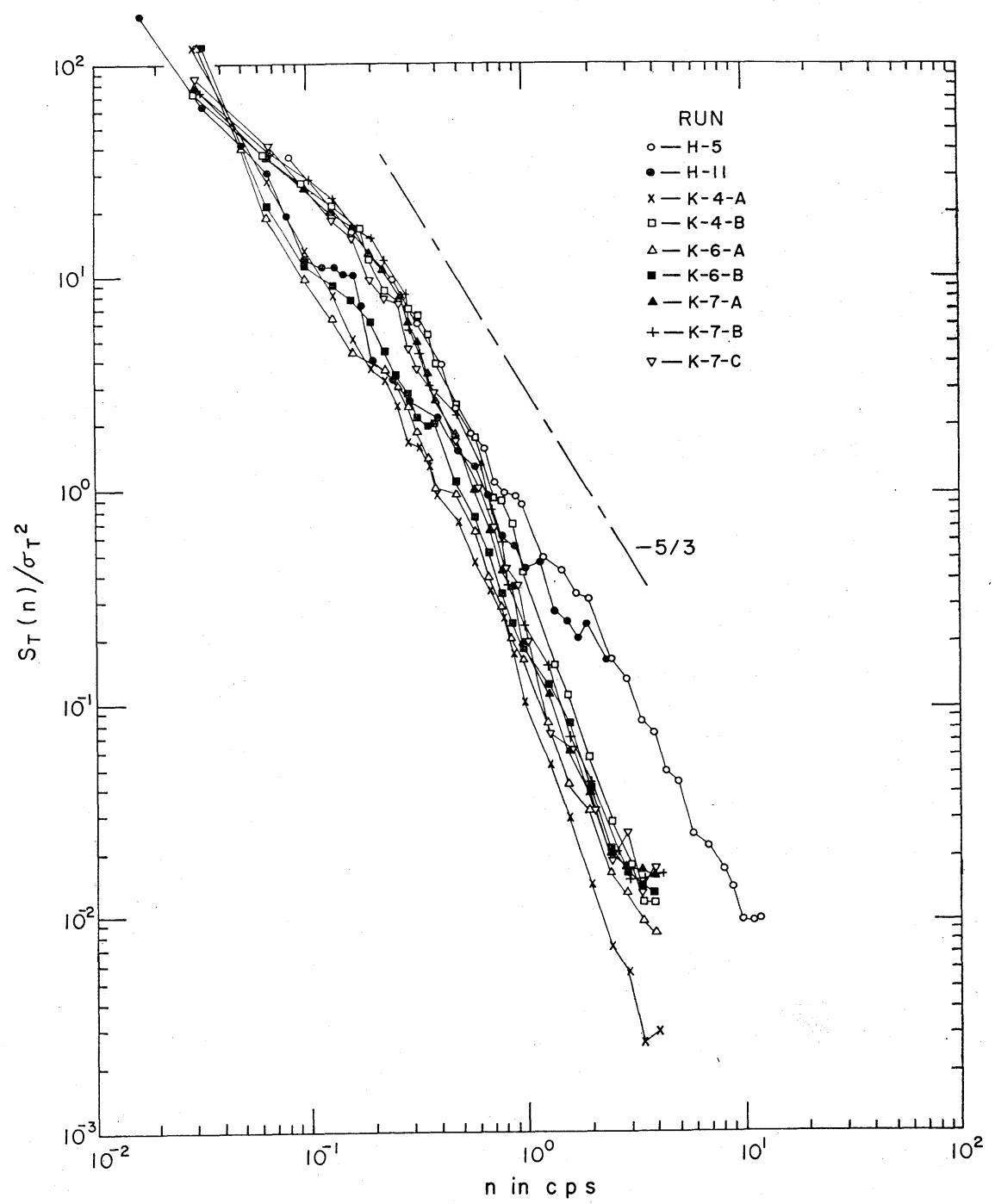

Fig. 17. Normalized temperature spectra for a selected number of runs. Again H-5 and H-11 were digitized by hand.

anemometer. For $\mathrm{K}-7$, both methods give downward fluxes but the magnitude of the sonic anemometer flux is considerably larger. The agreement of these two runs is less than desirable.

The variance spectra of $w$ were computed using the Blackman-Tukey procedure on the digital computer. The results are presented in Figs. 10 and 11. In the sediagrams the normalised spectral estimates have been plotted versus frequency. It appears that the runs directly read from the strip chart $(\mathrm{H}-5$ and $\mathrm{H}-11)$ follow the $-5 / 3$ law rather closely whereas all the runs digitised with the Beckman 210 show a steeper slope in the spectrum than corresponds to the inertial subrange. It is possible that the automatically digitised data have been subjected to filtering at lower frequencies than intended.

After extending the spectra to lower frequencies and by plotting $n S_{w}(n)$ versus $\log f$ (where $f=n z / \bar{u}, n=$ frequency, $z=$ height, and $\bar{u}=$ mean horizontal velocity), the position of the maximum of the spectra as a function of stability may be investigated. The spectra are plotted in Figs. 12, 13 and 14, and the peak frequency as a function of the Ri number is plotted in Fig. 15. These results confirm the findings of Panofsky and McCormick (1954) and Gurvich (1960).

Fig. 16 shows the ratio of $\sigma_{w} / u_{*}$ as a function 


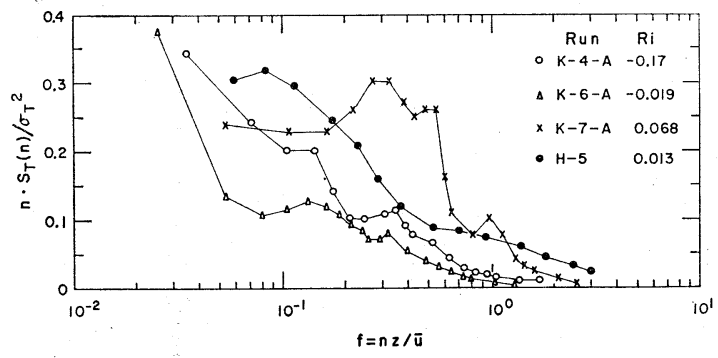

Fig. 18. Normalized temperature spectra for various stabilities.

of stability. The scatter is rather large which makes it difficult to see any trend with stability. The values of this ratio are in the same range as those quoted by Mordukhovich and Tsvang (1966) and by Busch and Panofsky (1968). More accurate observations concerning this point are needed.

Temperature spectra. The temperature sectra as given in Fig. 17 show a similar behavior as the spectra of the vertical wind component. Again the runs that were directly read from the strip chart show agreement with the $-5 / 3$ law whereas the data digitised with the Beckman 210 show a steeper slope. The maximum in the temperature spectrum occurs at rather low frequencies as can be seen in Fig. 18 where $n S_{T}(n)$ is plotted versus $\log f$. Actually the sampling period has been too short to determine the maximum except possibly for run $\mathrm{K}-7 \mathrm{~A}$ which is slightly stable.

Co-spectra of temperature and vertical wind component. Because the sonic anemometer measures temperature and wind simultaneously and at the same place, the data are excellently suited for determining the heat flow with the eddy correlation method. Actually the sonic temperature is the virtual temperature which deviates, depending on the humidity of the air, slightly from the true temperature. However, when observations are taken under fairly dry conditions, the error introduced by the sonic thermometer is usually negligible, see Kaimal and Businger (1963).

The cospectra between $w$ and $T$ are given in Fig. 19. The maxima of these spectra again appear to occur at higher frequencies with increasing stability, which is in agreement with other experimental work.

The coherence between $w$ and $T$ has been computed and plotted in Fig. 20 for three runs of different stability. The slightly stable case has

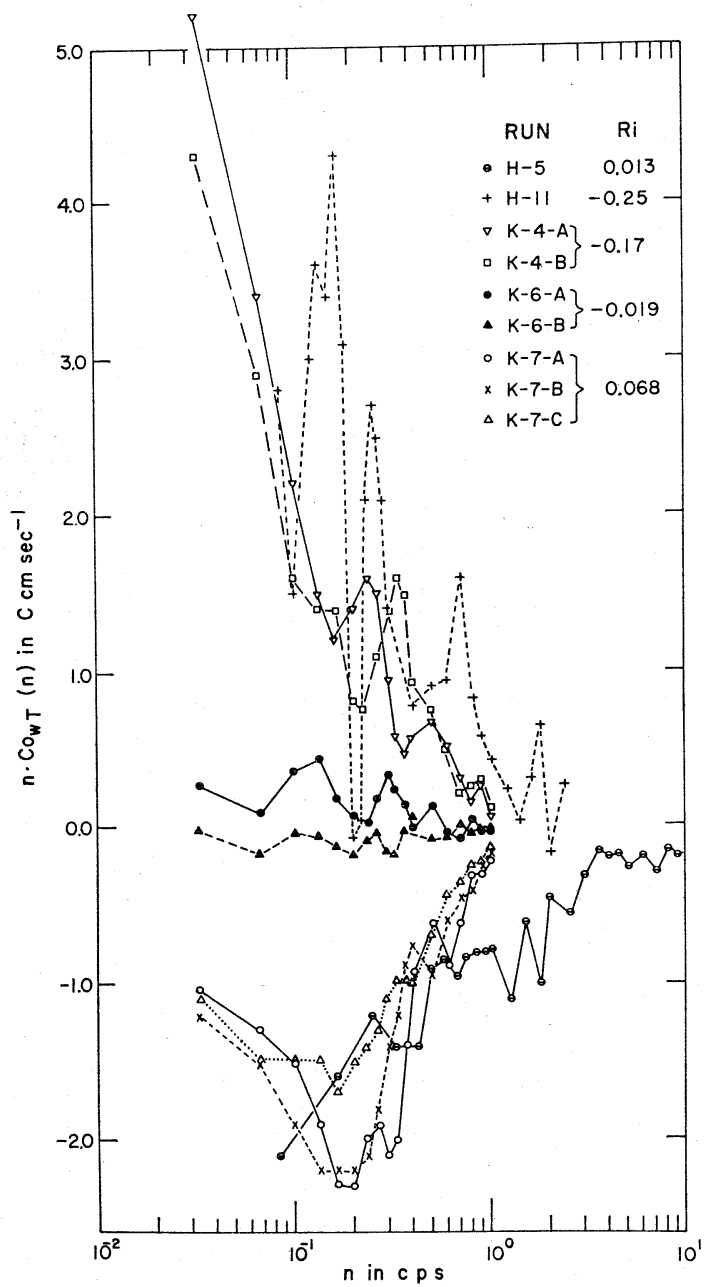

Fig. 19. Absolute co-spectra between $w$ and $T$ for a selected number of runs.

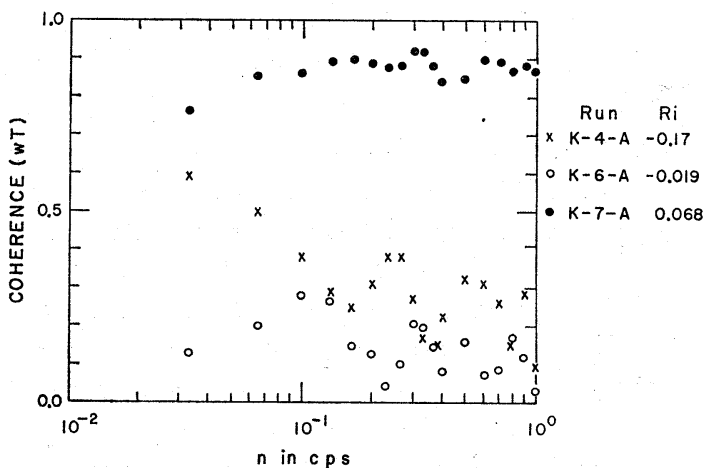

Fig. 20. Coherence between $w$ and $T$ for two unstable runs and one stable run.

a surprisingly large coherence in contrast to the slightly unstable case which has a remarkably low value. A high coherence value may be 
qualitatively expected under stable conditions because the temperature fluctuations may be partly associated with gravity waves which show perfect coherence between $w$ and $T$ but do not contribute to the heat flux. Under unstable conditions no such oscillations can be maintained and therefore no significant contribution from the quadrature spctrum is to be expected. This aspect of turbulence needs serious further study.

\section{Concluding remarks}

The sonic anemometer has proven to be a reliable instrument for the study of atmospheric turbulence. It is particularly well suited for the measurement of frequencies in the range of the energy containing eddies up to and including part of the inertial subrange. The path length over which the observations are taken is too large to measre the dissipation subrange. In order to cover entire spectrum, it is desirable to combine a sonic anemometer with a hot wire anemometer.

The information collected during the two expeditions reported in this paper has not been analysed in every detail. The time and effort required to do so is still considerable, so rather than delaying the paper further it was decided to present what is available at this stage.

\section{Acknowledgements}

The research reported in this paper has been supported in part by NSF Grant GF 271, JSPS Grant Chi-19 and NSF Grants GA-1099 and GP-4689. The cooperation of the Atmospheric Physics Group of Battelle Northwest at Hanford and of the Boundary Layer Branch of AFCRL has been essential to the success of the program. Much of the work with the analog computer has been carried out by K. Sahashi and N. Monji which has been greatly appreciated.

\section{References}

Barad, M.L. and J.J. Fuquay, 1962: The green glow diffusion program. Geophys. Res. Papers, No. 73, AFCRL.

Blackman, R.B. and J.W. Tukey, 1958: The measurement of power spectra, Dover, New York.

Boundary Layer Branch, 1967: Wind and temperature profiles from project Windy Acres, AFCRL-670339, Special Report No. 65, Bedford, Massachusetts.

Busch, N.E. and H.A. Panofsky, 1968: Recent spectra of atmospheric turbulence., Quart. J. Roy. meteor. Soc., 94, 132-148.

Gurvich, A.S., 1960: Frequency spectra and distribution functions of vertical wind components, Izvestia ANSSSR, Geophys. Ser. No. 7, 1042.

Kaimal, J.C. and J.A. Businger, 1963: A continuous wave sonic anemometer-thermometer, J. Appl. Met., 2, 156-164.

Mitsuta, Y., 1966: Sonic anemometer-thermometer for general use, J. meteor. Soc. Japan, 44, 12-23.

Mordukhovich, M.I. and L.R. Tsvang, 1966: Direct measurement of turbulent flows at two heights in the atmospheric ground layer, Izv. Acad. Nauk. SSSR, Atm. and Ocean. Phys., 2, 786-803.

Panofsky, H.A. and R.A. McCormick, 1954: Properties of spectra of atmospheric turbulence at 100 meters, Quart. J. Roy. meteor. Soc., 80, 546.

Paulson, C.A., 1967: Profiles of wind speed, temperature and humidity over the sea, Scientific Report (NSF GP-2418), Dept. Atmos. Sci., Univ. of Wash.

\title{
接地気層での超音波風速温度計の比較観測
}

\author{
J.A. Businger, M. Miyake \\ ワシントン大学 \\ 井上栄 \\ 光田寧, 花 房 竜 男 \\ 京都大学
}


気記録テープから A-D コンバーターによって機械的に数值化し，電子計算機によって計算する方法，扣よびアナ ログ的な磁気記録のままアナログ計算機によって処理する方法の3つの方法を用いて比較を行ったが，いずれの処 理方法によっても同じ結果が得られた.

観測值の比較の他に観測結果を用いて種々の安定度の下に抢ける地表面上での風速鉛直成分および気温の変動の スペクトルおよび両者のコヒーレンスの解析を行った。 